\title{
TRAJETÓRIA DA EDUCAÇÃO INCLUSIVA NO ENSINO MÉDIO INTEGRADO DA REDE FEDERAL: fatores de evasão e permanência
}

\author{
TRAYECTORIA DE LA EDUCACIÓN INCLUSIVA EN EL BACHILLERATO \\ RED FEDERAL INTEGRADA: factores de evasión y permanencia
}

\section{TRAJECTORY OF INCLUSIVE EDUCATION IN HIGH SCHOOL INTEGRATED FEDERAL NETWORK: factors of evasion and permanence}

\author{
Bruno J. B. Galasso ${ }^{1}$ \\ https://orcid.org/0000-0002-3677-7650 \\ Daisa Valverde dos Santos ${ }^{2}$ \\ https://orcid.org/0000-0001-7365-1873
}

\begin{abstract}
Resumo
O presente trabalho objetiva analisar os caminhos da Educação Inclusiva no Ensino Médio Integrado dos Institutos Federais de Educação, Ciência e Tecnologia. A pesquisa pode ser caracterizada como qualitativa, em que utiliza a pesquisa bibliográfica e documental para analisar os fatores de evasão e de permanência no trilhar dessas travessias. O corpus metodológico é desenhado através da literatura específica em língua portuguesa, no período de 2011 a 2020 , por consultas de artigos nas bases do SciELO, três livros, Arroyo (1991), Freire (1996), Mantoan (2003), dois decretos sobre a temática, dois Planos Estratégicos para Permanência e Êxito dos estudantes e dois Regulamentos dos Núcleos de Atendimento às Pessoas com Necessidades Específicas (NAPNE), a fim de fundamentar a discussão dos resultados. A conclusão do estudo revelou a complexidade da temática e a corresponsabilidade institucional dos agentes educativos para o fortalecimento da Educação Profissional Tecnológica Inclusiva. Percebe-se a necessidade em repensar o modelo educacional vigente, o Ensino Médio Integrado e o lugar da inclusão. Mais do que nunca, é preciso "tecer a rede" e, para isso, é preciso um longo debate, além de pesquisas e de investimentos.
\end{abstract}

Palavras-chave: Evasão escolar. Educação profissional. Inclusão Educacional.

\section{Resumen}

Este trabajo tiene como objetivo analizar los caminos de la Educación Integrada en el Bachillerato Integrado de los Institutos Federales de Educación, Ciencia y Tecnología. La investigación se puede caracterizar como cualitativa, en la que utiliza la investigación bibliográfica y documental para

\footnotetext{
${ }^{1}$ Doutor em Educação pela Universidade de São Paulo (USP). Professor do Instituto Nacional de Educação de Surdos (INES) e do Instituto Politécnico do Porto (IPP). E-mail: galasso.bruno@gmail.com

${ }^{2}$ Mestranda do Programa de Pós-Graduação em Formação de Professores e Práticas Interdisciplinares (PPGFPPI) Universidade de Pernambuco (UPE). E-mail: daisa.valverde@gmail.com
}

\section{Como referenciar este artigo:}

GALASSO, B. J. B.; SANTOS, D. V. Trajetória da educação inclusiva no ensino médio integrado da rede federal: fatores de evasão e permanência. Revista Pedagógica, v. 23, p. 1-20, 2021 
analizar los factores de evasión y permanencia en el recorrido de estos cruces. El corpus metodológico se diseña a través de literatura específica en portugués, en el período de 2011 a 2020, mediante la consulta de artículos sobre las bases SciELO, tres libros Arroyo (1991), Freire (1996), Mantoan (2003), dos decretos sobre la temática, dos Planes Estratégicos para la Permanencia y Éxito de los estudiantes y dos Reglamentos de los Centros de Atención a Personas con Necesidades Específicas (NAPNE), con el fin de apoyar la discusión de los resultados. La conclusión del estudio reveló la complejidad del tema y la corresponsabilidad institucional de los agentes educativos para fortalecer la Educación Profesional Tecnológica Inclusiva. Es necesario repensar el modelo educativo actual, el Bachillerato Integrado y el lugar de inclusión. Más que nunca es necesario "tejer la red" y, para eso, se necesita un largo debate, además de investigación e inversiones.

Palabras clave: deserción escolar. Educación profesional. Inclusión educativa.

\begin{abstract}
This work aims to analyze the paths of Inclusive Education in Integrated High School of the Federal Institutes of Education, Science and Technology. The research can be characterized as qualitative, in which it uses bibliographic and documentary research to analyze the factors of evasion and permanence in the journey of these crossings. The methodological corpus is designed through specific literature in Portuguese, in the period from 2011 to 2020, by consulting articles on the SciELO bases, three books Arroyo (1991), Freire (1996), Mantoan (2003), two decrees on the thematic, two Strategic Plans for the Permanence and Success of students and two Regulations of the Centers for Assistance to People with Specific Needs (NAPNE), in order to support the discussion of the results. The conclusion of the study revealed the complexity of the theme and the institutional co-responsibility of the educational agents to strengthen Inclusive Technological Professional Education. There is a need to rethink the current educational model, Integrated High School and the place of inclusion. More than ever, it is necessary to "weave the network" and, for that, it takes a long debate, in addition to research and investments.
\end{abstract}

Keywords: School dropout. Professional education. Educational Inclusion.

\title{
INTRODUÇÃO
}

De acordo com a Constituição Federal (CF), a educação é um dos direitos fundamentais que deve ser garantido aos cidadãos (BRASIL, 1988). Segundo a Lei de Diretrizes e Bases da Educação (LDB) 9.394/96, os princípios ligados ao padrão de qualidade educacional, a valorização do profissional da educação e a vinculação entre a educação escolar, o trabalho e as práticas sociais, apontam o caminho para que o alunado se desenvolva de forma efetiva e favoreça a permanência e o êxito estudantil (BRASIL, 1996).

Nesse sentido, faz-se necessário considerar a trajetória de lutas para a democratização do ensino no Brasil, bem como reconhecer alguns desafios em torno da formação e da valorização dos profissionais de educação, principalmente em relação às 
barreiras encontradas pela implantação e pela implementação de uma escola realmente inclusiva. A LDB estabelece a importância da educação inclusiva em seu Artigo 58, "Entende-se por educação especial, para os efeitos desta Lei, a modalidade de educação escolar oferecida preferencialmente na rede regular de ensino, para educandos com deficiência, transtornos globais do desenvolvimento e altas habilidades ou superdotação" (BRASIL, 1996).

Nas últimas décadas, avanços significativos ${ }^{3}$ tornaram real o acesso dos estudantes com necessidades educacionais específicas nos espaços educativos (MACHADO et al, 2015). Diante de todo este aparato legal, cria-se uma sistematização jurídica para o acolhimento e permanência dos estudantes com necessidades específicas, principalmente na educação básica. No entanto, percebe-se nas instituições de ensino o descumprimento dos inúmeros documentos citados neste estudo. Isso porque, o caráter legal ainda não possibilitou a implementação de medidas efetivas, como a formação específica de professores, adequação de materiais, contratação de intérpretes da Língua Brasileira de Sinais (GALASSO et al, 2017). Por este motivo, as lutas pela inclusão encontram discriminação, preconceito, falta de conhecimento dos direitos adquiridos, rejeição familiar etc. Estes são alguns gargalos diagnosticados na educação inclusiva no âmbito da Rede Federal, objeto de estudo dessa pesquisa, que tem a missão de aliar formação humana à formação profissional.

Os Institutos Federais de Educação, Ciência e Tecnologia foram criados a partir da Lei $n^{\circ} 11.892 / 2008$ (BRASIL, 2008). De acordo com o Art. $6^{\circ}$ desta Lei, os Institutos Federais (IF) têm dentre as suas finalidades e suas características: ofertar educação profissional e tecnológica, em todos os seus níveis e suas modalidades, formando e qualificando cidadãos com vistas à atuação profissional nos diversos setores da economia, com ênfase no desenvolvimento socioeconômico local, regional e nacional.

\footnotetext{
3 Ratifica-se uma profusão de documentos fortalecendo a inclusão educacional nas escolas públicas, tais como: Lei $\mathrm{n}^{\circ}$ 9.394/1996, Lei de Diretrizes e Bases da Educação (LDB); Lei n 8.069/1990, Estatuto da Criança e do Adolescente; Lei ${ }^{\circ}$ 10.172/2001, Plano de Desenvolvimento da Educação (PDE); Política de Educação Especial na perspectiva da Educação Inclusiva/2008; Decreto 7.611/2011, sobre o Atendimento Educacional Especializado; Decreto ${ }^{\circ} 7.234 / 2010$, Programa Nacional de Assistência Estudantil (PNAES); Plano Nacional de educação (2014/2024); Lei nº 13.146/2015, Lei Brasileira de Inclusão da Pessoa com Deficiência (Estatuto da Pessoa com Deficiência); Lei n 13.409/2006, reserva de vagas para pessoas com deficiência nos cursos técnico de nível médio e superior das Instituições Federais de Ensino; além dos documentos internacionais como a Declaração de Salamanca/1994, Convenção da Guatemala/2001, Convenção sobre os Direitos das Pessoas com Deficiência/2006 - Aprovada pela ONU, entre outros.
} 
Revista do Programa de Pós-Graduação em Educação da Unochapecó

ISSN 1984-1566 (on-line) ISSN 1415-8175 (impressa)

Nos últimos dez anos, os IF vêm passando por um processo de expansão e de interiorização do ensino profissional com a finalidade de democratizar a sua oferta no Brasil e com o intuito de contribuir para o processo de inclusão social.

Destarte, a expansão e a interiorização da Rede Federal de Ensino é o encontro das diferenças, dos sotaques, da diversidade cultural, social e política. Ao longo do novo desenho institucional da educação profissional pública brasileira, a acessibilidade, a permanência e o êxito ganharam um destaque e várias iniciativas de combate à evasão e à retenção estão sendo realizadas. Dentre estas, a ampliação dos recursos, com destaque ao Decreto n 7.234/2010, Programa Nacional de Assistência Estudantil (PNAES), no Art. $3^{\circ}$,

As ações de Assistência Estudantil do PNAES deverão ser desenvolvidas nas seguintes áreas: I - moradia estudantil; II - alimentação; III - transporte; IV - atenção à saúde; V - inclusão digital; VI - cultura; VII - esporte; VIII - creche; IX - apoio pedagógico; e X - acesso, participação e aprendizagem de estudantes com deficiência, transtornos globais do desenvolvimento e altas habilidades e superdotação (BRASIL, 2010).

Nessa perspetiva, os IFs possuem uma função social e inclusiva. Acolher estudantes de várias classes sociais e etnias, reservando também o lugar para pessoas com deficiência nos cursos técnicos de níveis médio e superior, alinhado ao princípio educativo do trabalho e à formação omnilateral.

Nessa conjuntura é fundamental o desenvolvimento de ações de enfrentamento ao combate da evasão, por se tratar de um fator de alta complexidade no âmbito da Rede Federal, problemática que também atinge estudantes público-alvo da educação especial. Assim, o desafio científico da proposta deste trabalho tem sua nascente nesse emaranhado de possibilidades e diversidades, de vozes e de silêncios, nos caminhos percorridos pela educação inclusiva ofertada no Ensino Médio Integrado (EMI) na Rede Federal.

Diante disso, o objetivo deste trabalho é analisar, através de estudos já realizados na área de conhecimento e da literatura específica, quais os fatores de evasão e de permanência durante a travessia desses estudantes do EMI da Rede Federal de Educação Profissional e Tecnológica. Além disso, pretende-se mapear dados por meio da revisão bibliográfica acerca de estudos sobre evasão e permanência dos estudantes com deficiência dos Institutos Federais, identificar as barreiras encontradas por eles durante a 
Revista do Programa de Pós-Graduação em Educação da Unochapecó

ISSN 1984-1566 (on-line) ISSN 1415-8175 (impressa)

travessia do EMI e corroborar para o desenvolvimento da cultura da "educação para convivência" com base na aceitação da diversidade.

\section{METODOLOGIA}

Esta pesquisa é caracterizada como qualitativa, do tipo estado do conhecimento, com base em levantamento e em análise bibliográfica de livros, artigos científicos e de outros documentos. Fachin (2006) destaca:

\footnotetext{
Entende-se que a pesquisa bibliográfica, em termos genéricos, é um conjunto de conhecimentos reunidos em obras de toda natureza. Tem como finalidade conduzir o leitor à pesquisa de determinado assunto, proporcionando o saber. Ela se fundamenta em vários procedimentos metodológicos, desde a leitura até como selecionar, fichar, organizar, arquivar, resumir o texto; ela é a base para as demais pesquisas (FACHIN, 2006, p.120).
}

A revisão bibliográfica teve por finalidade a construção de uma contextualização sobre a problemática e a análise das possibilidades contidas no material das leituras consultadas. Foi adotada uma seleção de trabalhos na plataforma Scientific Electronic Library Online - SciELO. Na busca, foram utilizados os descritores: educação profissional AND deficiência visual (15 artigos); evasão AND cursos técnicos (44 trabalhos); deficiência AND ensino médio (7 artigos); inclusão AND deficiência (15 artigos).

Diante dessa amostra, delimitamos um recorte entre 2011 e 2020, possibilitando uma visão mais ampla, investigativa e interpretativa do cenário educacional decorrente da implantação dos Institutos Federais, visto que educação especial e inclusiva é um tema pouco explorado nas produções acadêmicas da Educação Profissional. Foram priorizados os trabalhos completos em língua portuguesa e que estivessem disponíveis on-line.

Após esta etapa, foi realizada uma leitura dos resumos a fim de mapear os trabalhos que abordassem os fatores de evasão e de permanência durante a travessia desses estudantes do EMI da Rede Federal de Educação Profissional e Tecnológica. Assim, de acordo com a delimitação do escopo do trabalho, o caminho metodológico da pesquisa foi desenhado por dois artigos; também foram selecionados três livros, dois decretos, dois planos estratégicos para permanência e êxito dos estudantes dos Institutos Federais e dois Regulamentos dos Núcleos de Atendimento às Pessoas com Necessidades Específicas 
Revista do Programa de Pós-Graduação em Educação da Unochapecó

ISSN 1984-1566 (on-line) ISSN 1415-8175 (impressa)

(NAPNE), a fim de fundamentar a discussão dos resultados, que tratam da questão relativa ao tema, conforme apresentado no Quadro abaixo.

Quadro 1 - Documentos Analisados

\begin{tabular}{|l|}
\hline \multicolumn{1}{|c|}{ Livros: } \\
\hline $\begin{array}{l}\text { Revendo os vínculos entre trabalho e educação: elementos materiais da formação humana; Pedagogia da } \\
\text { autonomia: saberes necessários à prática educativa; Inclusão Escolar: O que é? Por que? Como fazer? }\end{array}$ \\
\hline \multicolumn{1}{|c|}{ Artigos: } \\
\hline $\begin{array}{l}\text { Permanência e evasão na educação técnica de nível médio em Minas Gerais; Formação continuada de } \\
\text { professores do Ensino Médio Integrado do IFRN na perspectiva da inclusão de alunos com deficiência visual. }\end{array}$ \\
\hline \multicolumn{1}{|c|}{ Documentos: } \\
\hline $\begin{array}{l}\text { Programa Nacional de Assistência Estudantil, Decreto no }{ }^{\circ} 7234 / 2010 ; \text { Atendimento Educacional Especializado } \\
\text { (AEE), Decreto } n^{\circ} 7611 / 2011 ; \text { Planos de Permanência e êxito: Instituto Federal de Educação, Ciência e } \\
\text { Tecnologia do Ceará e Instituto Federal de Educação, Ciência e Tecnologia do Pará; Regulamentos NAPNEs: } \\
\text { Instituto Federal de Educação, Ciência e Tecnologia de Rondônia e Instituto Federal de Educação, Ciência e } \\
\text { Tecnologia do Rio Grande do Sul. }\end{array}$ \\
\hline
\end{tabular}

Fonte: Elaborado pelos autores (2020).

\section{HISTÓRICO DOS INSTITUTOS FEDERAIS NO PAÍS}

Segundo Rocha (2013), a trajetória dos Institutos Federais (IF) tem início a partir de 1909, quando o Presidente Nilo Peçanha cria as Escolas de Aprendizes e Artífices nas capitais dos estados brasileiros, através do Decreto $n^{\circ} 7 \cdot 566$, oferecendo Educação Profissional para a população em situação de vulnerabilidade socioeconômica. Estas escolas deram início à Rede Federal, que culminou nas Escolas Técnicas e, posteriormente, nos Centros Federais de Educação Tecnológica (CEFET). A partir de 2008, através da Lei nº 11.892, os CEFET, as Escolas Agrotécnicas e as Escolas Técnicas passaram a compor a Rede Federal de Ensino Profissional.

Com a consolidação da Rede Federal e da Educação Profissional e Tecnológica ao longo dos últimos dez anos, a democratização do ensino teve um significativo crescimento, assim como a expansão e a interiorização do Ensino Profissional, possibilitando mais acesso aos estudantes oriundos das diversas camadas sociais. Porém, os índices de evasão estudantil contrariam a tríade da universalização do ensino (o acesso, a permanência e o êxito), especificamente dos Institutos Federais (IFs). 
Revista do Programa de Pós-Graduação em Educação da Unochapecó

ISSN 1984-1566 (on-line) ISSN 1415-8175 (impressa)

O perfil dos estudantes da Rede Federal é composto pela busca de uma Educação Básica de qualidade, principalmente visando ao Exame Nacional do Ensino Médio (ENEM) e também à construção de uma trajetória profissional, com condições favoráveis à sua formação e posterior inserção para atuar no mundo do trabalho. Para Dore e Lüscher (2011, p. 10), as “possibilidades de acesso ao ensino técnico aumentaram tanto pela política educacional quanto por fatores relacionados ao desempenho escolar dos estudantes na educação básica”. Para os estudantes que conseguem ultrapassar todas as barreiras e se matricular em um Curso Técnico, resta ainda o desafio de superar as condições nem sempre favoráveis à permanência na escola.

Segundo o Censo Escolar da Educação Básica de 2019, realizado pelo Instituto Nacional de Estudos e Pesquisas Educacionais Anísio Teixeira (INEP), houve um crescimento nas matrículas na Educação Profissional: a forma integrada ao Ensino Médio, que teve acréscimo de 38,6 mil (6,6\%) estudantes, e a forma Subsequente (cursada após a conclusão do ensino médio), com 68 mil matrículas a mais (7,6\%) no ano (INEP, 2019).

Aqui temos um fator importante acerca das dificuldades encontradas pelos estudantes, pois apesar do acesso ao curso garantido pela legislação, diversos fatores que interromper a trajetória do alunado (materiais didáticos específicos, currículo não adaptado, falta de formação de professores), ocorrendo a evasão do curso e da instituição. O termo evasão tem sido objeto de estudo em diversas pesquisas e seus fatores chocam com a própria legislação, especificamente em alguns princípios da LDB: a igualdade de condição para o acesso e a permanência na escola, a garantia do padrão de qualidade, a vinculação entre a educação escolar, o trabalho e as práticas sociais. Dore e Lüscher (2011) acrescentam que:

As possíveis causas da evasão são extremamente difíceis de serem identificadas porque, de forma análoga a outros processos vinculados desempenho escolar, a evasão é influenciada por um conjunto de fatores que se relacionam tanto ao estudante e à sua família quanto à escola e à comunidade em que vive (DORE; LÜSCHER, 2011, p. 386).

Assim, faz-se necessário analisar a evasão como uma rede de complexidade tecida por fatores individuais, sociais, econômicos, culturais e acadêmicos que podem interromper a travessia do estudante em sua caminhada escolar. Este fenômeno pode 
Revista do Programa de Pós-Graduação em Educação da Unochapecó

ISSN 1984-1566 (on-line) ISSN 1415-8175 (impressa)

contribuir para a manutenção do status quo e a permanente desigualdade social, tornando, assim, mais distante o direto do bem social, que é a educação (SILVA et all, 2021).

Estamos diante de um quadro reprodutor da nobre e da nutrida divisão de classes, um sistema educacional agenciado pelo capital e por uma estrutura social de opressores e de oprimidos. O acesso ao conhecimento ainda é corrompido pelos privilégios concebidos aos "nobres", enquanto que os plebeus agonizam por mais oportunidades. Esta fratura social é representada nos espaços educativos, pois:

É essa escola das classes trabalhadoras que vem fracassando em todo lugar. Não são as diferenças de clima ou de região que marcam as grandes diferenças entre escola possível ou impossível, mas as diferenças de classe. As políticas oficiais tentam ocultar esse caráter de classe no fracasso escolar, apresentando os problemas e as soluções com políticas regionais e locais (ARROYO, 1991, p. 21).

As marcas da evasão advêm da permanente e da histórica desigualdade social brasileira. Quando um estudante não conclui sua travessia escolar, todos perdem, ocasionando prejuízos para o indivíduo e para o social (família, instituição, sociedade), potencializando o trabalho informal, o subemprego, a desvalorização e a exploração humana. O ciclo da pobreza laboral é alimentado, tornando a exclusão social algo natural e comum. Essa desigualdade é refletida nos espaços educativos, em que a raiz da dualidade escolar é nutrida pelos oprimidos, que usam a força do trabalho, e pelos opressores, que dominam a massa, que determinam o que ensinar, o que aprender, o controle e o poder, e que definem a "grade" curricular da Educação Infantil ao Ensino Superior, saberes controlados e produzidos a serviço do capital.

É no pensamento freiriano que encontramos uma resistência e um enfrentamento a essa perversa desigualdade social, em defesa da humanização e da transformação baseada na crítica, uma luta de décadas contra a exploração e a injustiça social, o que é exposto pelo educador:

Daí a crítica permanentemente presente em mim à malvadez neoliberal, ao cinismo de sua ideologia fatalista e a sua recusa inflexível ao sonho e à utopia. Daí a minha raiva, legítima raiva, que envolve o meu discurso quando me refiro às injustiças a que são submetidos os esfarrapados do mundo (FREIRE, 1996 p.15).

A partir dos pontos elencados, compreendemos os mecanismos que produzem a exclusão social. Estes estão acoplados ao modelo de sociedade, determinando o modelo 
de escola, de currículo, de avaliação, de acesso, de permanência. Assim, consequentemente, os estudantes provenientes das camadas populares serão os mais atingidos pelo fenômeno da evasão.

Tal fenômeno merece um olhar atento e um estudo diante da realidade de muitos espaços educativos, especificamente os Institutos Federais (IFs) que, mesmo com uma estrutura diferente das escolas públicas do país e com alto investimento, com arquitetura planejada, laboratórios das variadas áreas do conhecimento, equipe multidisciplinar, corpo docente com titulação de mestrado e de doutorado, bibliotecas, salas climatizadas e auxílio estudantil, possuem significativo índice de evasão. A escassez de informações no campo teórico e empírico comprova a necessidade de pesquisas na área para dirimir e para combater os danos da evasão na trajetória dos estudantes, na família, nas instituições e na sociedade.

A evasão nos Cursos Técnicos aparece como um fosso no estudo realizado pelo Tribunal de Contas da União (TCU) presente no Relatório de Auditoria da Rede Federal. Assim, foi criado um Acórdão, n 506/2013, entre a Secretaria de Educação Profissional e Tecnológica (SETEC) e os Institutos Federais (IFs), na busca de reduzir o fenômeno da evasão, estabelecendo possíveis estratégias de enfrentamento da problemática, com mapeamento de dados dos cursos ofertados (BRASIL, 2013).

O documento revela a necessidade de trabalho institucional direcionado aos eixos de permanência e de êxito, com a orientação de um plano de ações/metas/estratégias envolvendo todos os agentes educativos. Haja vista a necessidade de pesquisas que aprofundem as questões entre educação profissional e evasão, consolida-se a importância de mais estudos que apontem caminhos para superação dessa problemática e das experiências vivenciadas nas 643 unidades dos IFs espalhadas pelo território brasileiro, decorrentes de cada plano institucional de permanência e de êxito. Assim, boa parte dos IFs já elaborou seus planos estratégicos, enquanto outra parte está em fase de construção.

Importante ressaltar que a Rede Federal, enquanto política pública de inclusão social, vem obedecendo a legislação, cumprindo, em seus processos seletivos, o respeito ao sistema de cotas, assegurando 50\% das vagas reservadas para estudantes egressos de escolas públicas, $45 \%$ das vagas para a ampla concorrência e $5 \%$ para candidatos com deficiências. 
Revista do Programa de Pós-Graduação em Educação da Unochapecó

ISSN 1984-1566 (on-line) ISSN 1415-8175 (impressa)

Consideravelmente as políticas de inclusão contribuem com o avanço da diversidade e da democratização do acesso aos espaços educativos e representam a intensificação da luta pela construção de uma sociedade inclusiva. Como destaca o estudo de Mantoan (2003, p.16) “o direito à diferença nas escolas desconstrói, portanto, o sistema atual de significação escolar excludente, normativo, elitista, com suas medidas e seus mecanismos de produção da identidade e da diferença".

No contexto da Educação Profissional, temos verificado a inserção de estudantes público-alvo da educação especial, respeitando o direito estabelecido na Lei nº 9.394/1996 (LDB), que em seu Art. 59 estabelece que:

\begin{abstract}
Os sistemas de ensino assegurarão aos educandos com deficiência, transtornos globais do desenvolvimento e altas habilidades ou superdotação: (...) IVeducação especial para o trabalho, visando a sua efetiva integração na vida em sociedade, inclusive em condições adequadas para os que não revelarem capacidade de inserção no trabalho competitivo (BRASIL, 1996).
\end{abstract}

Entende-se pessoa com deficiência "aquela que tem impedimento de longo prazo de natureza física, mental, intelectual ou sensorial que comprometem a participação plena e efetiva na sociedade em igualdade de condições com os demais" (BRASIL, 2015), consonante com a Lei Brasileira de Inclusão, n 13.146/2015, também conhecida como Estatuto da Pessoa com Deficiência.

Nosso foco é o encontro da educação especial e inclusiva, alinhada à formação dos estudantes com deficiência, ao acesso desse público nos Cursos Técnicos, aos fatores de permanência e à evasão durante essa travessia.

Diante desta fundamentação, a instituição escolar deve direcionar ações para mudanças significativas, voltadas para o acolhimento e para a trajetória educacional dos estudantes com deficiência, tendo em vista o número crescente das matrículas na Educação Profissional do público-alvo da educação especial, na esfera Federal, conforme a figura 1:

Figura 1 - Percentual de alunos de 4 a 17 anos da educação especial incluídos em classes comuns por dependência administrativa 2015-2019

\begin{tabular}{|c|c|c|c|c|c|c|}
\hline \multirow[b]{2}{*}{ Ano } & \multicolumn{6}{|c|}{ Dependência Administrativa } \\
\hline & Total & Pública & Federal & Estadual & Municipal & Privada \\
\hline
\end{tabular}


Revista do Programa de Pós-Graduação em Educação da Unochapecó

ISSN 1984-1566 (on-line) ISSN 1415-8175 (impressa)

\begin{tabular}{|l|l|l|l|l|l|l|}
\hline 2015 & $88,4 \%$ & $95,8 \%$ & $73,4 \%$ & $96,1 \%$ & $95,8 \%$ & $41,0 \%$ \\
\hline 2016 & $89,5 \%$ & $96,3 \%$ & $79,6 \%$ & $96,6 \%$ & $96,2 \%$ & $44,2 \%$ \\
\hline 2017 & $90,9 \%$ & $96,8 \%$ & $82,1 \%$ & $97,4 \%$ & $96,6 \%$ & $47,6 \%$ \\
\hline 2018 & $92,1 \%$ & $97,3 \%$ & $86,7 \%$ & $98,0 \%$ & $97,1 \%$ & $51,8 \%$ \\
\hline 2019 & $92,8 \%$ & $97,6 \%$ & $90,1 \%$ & $98,3 \%$ & $97,4 \%$ & $56,7 \%$ \\
\hline
\end{tabular}

Fonte: INEP (2019).

Com base no Censo Escolar da Educação Básica elaborado pelo Instituto Nacional de Estudos e Pesquisas Educacionais Anísio Teixeira (INEP), houve um relevante aumento do acesso dos estudantes da educação especial na Rede Federal, o que requer planejamento de ações para acolher e para garantir a permanência e o êxito deste público. Alguns fatores relevantes para essa garantia nasceram da ação do Programa de Educação, Tecnologia e Profissionalização para Pessoas com Necessidades Educacionais Especiais, chamado de TEC NEP. A implantação do Núcleo de Atendimento às Pessoas com Necessidades Educacionais Especiais (NAPNE) deverá dispor de infraestrutura necessária para instalações da sede e de tecnologia assistida (jogos pedagógicos acessíveis, lupas manuais e eletrônicas, impressora e máquina Braille, tablets, reglete, punção, soroban, guia de assinatura, calculadora sonora, hardwares e softwares, colmeia, estratégias e metodologias ativas).

Trazemos como exemplo o Regulamento do NAPNE do Instituto Federal de Educação, Ciência e Tecnologia de Rondônia (2016), acerca da finalidade do núcleo, com destaque ao Art. $3^{\circ}$, em que “o NAPNE tem por finalidade a promoção da educação para a convivência, a partir do respeito às diferenças e à igualdade de oportunidades, que venha a eliminar as barreiras atitudinais, comunicacionais e arquitetônicas no IFRO”. Além disso, os Núcleos possuem o papel de promover, de facilitar e de garantir a inclusão dos alunos com deficiência nos IF, seja na educação básica ou nos diversos cursos técnicos e tecnológicos.

Mais uma finalidade do NAPNE, de acordo com o Regulamento do Instituto Federal de Educação, Ciência e Tecnologia do Rio Grande do Sul (2014), em seu Art. 2º é "integrar os diversos segmentos que compõem a comunidade, propiciando sentimento de 


\section{REVISTA}

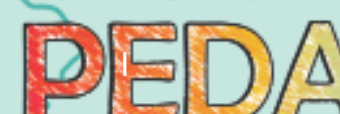

Revista do Programa de Pós-Graduação em Educação da Unochapecó

ISSN 1984-1566 (on-line) ISSN 1415-8175 (impressa)

corresponsabilidade na construção da ação educativa de inclusão na Instituição". Evidenciamos, assim, a importância do termo corresponsabilidade, sensibilizando toda comunidade para o apoio e o acolhimento dos estudantes em todas as atividades acadêmicas da instituição.

É válido destacar que nem todas as unidades dos IFs possuem o NAPNE - ou o profissional do Atendimento Educacional Especializado (AEE) - indo de encontro ao Decreto $n^{\circ}$ 7.611/2011, que estabelece o Atendimento Educacional Especializado (BRASIL, 2011). Urge em cada unidade o direcionamento de ações para o cumprimento do que determina a legislação, assim como os planos estratégicos institucionais de permanência e de êxito elencados através do Acordão n 506/2013 (BRASIL, 2013).

Alguns fatores encontrados na Rede Federal que colaboram para a permanência e o êxito dos estudantes com baixa visão são: a implantação do NAPNE e de práticas inclusivas alinhadas com toda a comunidade acadêmica (estudantes, técnicos administrativos e docentes); os planos estratégicos institucionais de permanência e de êxito; a grande área da tecnologia assistiva; e a institucionalização do AEE. Os IFs possuem infraestrutura favorável ao projeto de sociedade inclusiva, quando se compara com as demais escolas brasileiras, pois possuem salas de aulas amplas e climatizadas, laboratórios, bibliotecas, banheiros com acessibilidade, sinalização e piso tátil, além de vários recursos tecnológicos, com um percentual bastante significado, retratado na leitura da figura 2:

Figura 2 - Disponibilidade (\%) de recursos tecnológicos nas escolas de ensino médio por dependência administrativa, segundo o recurso 2019

\begin{tabular}{|c|c|c|c|c|c|c|}
\hline \multicolumn{7}{|c|}{ Dependência Administrativa } \\
\hline Recurso & Total & Pública & Federal & Estadual & Municipal & Privado \\
\hline Lousadigital & $27,7 \%$ & $28,7 \%$ & $44,4 \%$ & $28,4 \%$ & $\nabla, 0 \%$ & $25,3 \%$ \\
\hline Projetormultimídia & $84, \%$ & $83,4 \%$ & $96,8 \%$ & $83, \%$ & $76, \%$ & $85,8 \%$ \\
\hline $\begin{array}{l}\text { Computador de } \\
\text { mesa para alunos }\end{array}$ & $78, \%$ & $79,0 \%$ & $93,3 \%$ & $78,7 \%$ & $617 \%$ & $75,8 \%$ \\
\hline $\begin{array}{l}\text { Computador portátil } \\
\text { para alunos }\end{array}$ & $41,7 \%$ & $38,6 \%$ & $44,9 \%$ & $38,5 \%$ & $35, \%$ & $49,2 \%$ \\
\hline Tablet para alunos & $20,0 \%$ & $5,7 \%$ & $25,8 \%$ & $5,4 \%$ & $7,4 \%$ & $30,7 \%$ \\
\hline Internet para alunos & $62,3 \%$ & $61,9 \%$ & $96,8 \%$ & $61,0 \%$ & $44,7 \%$ & $63,2 \%$ \\
\hline $\begin{array}{l}\text { Internet para uso } \\
\text { administrativo }\end{array}$ & $88,8 \%$ & $88,5 \%$ & $97,8 \%$ & $88,3 \%$ & $82,4 \%$ & $89,6 \%$ \\
\hline
\end{tabular}


Revista do Programa de Pós-Graduação em Educação da Unochapecó

ISSN 1984-1566 (on-line) ISSN 1415-8175 (impressa)

\begin{tabular}{|l|l|l|l|l|l|l|}
\hline $\begin{array}{l}\text { Internet para } \\
\text { ensino e } \\
\text { aprendizagem }\end{array}$ & $68,0 \%$ & $66,2 \%$ & $86,2 \%$ & $65,8 \%$ & $52,7 \%$ & $72,3 \%$ \\
\hline
\end{tabular}

Fonte: INEP (2019).

No trilhar deste estudo, reconhecemos os avanços, mesmo que ainda tímidos, em relação ao cumprimento da legislação, voltados para a população de estudantes com deficiência, e o rompimento das barreiras pela garantia do êxito estudantil no âmbito da Rede Federal.

Assim, o processo inclusivo vai além da capacitação de profissionais, envolve um conjunto de elementos, tais como "aquisição de recursos pedagógicos adaptados, a preparação dos diversos recursos humanos existentes na escola, a eliminação de barreiras físicas e atitudinais. Contudo, o professor ainda é o elemento central desse processo" (FORTES; MARTINS, 2017, p. 34).

Alguns fatores e motivações da evasão foram elencados no Quadro 2 após análise dos Planos Estratégicos Institucionais de permanência e de êxito do Instituto Federal de Educação, Ciência e Tecnologia do Pará (2017) e do Instituto Federal de Educação, Ciência e Tecnologia do Ceará (2020), elaborados respectivamente em 2016 e em 2017.

Quadro 2 - PLANOS DE PERMANÊNCIA E DE ÊXITO

\begin{tabular}{|c|c|}
\hline IFPA & IFCE \\
\hline \multicolumn{2}{|c|}{ FATORES DE EVASÃO } \\
\hline Dificuldades financeiras & $\begin{array}{c}\text { Pouca ou nenhuma adaptação de avaliações às } \\
\text { necessidades educacionais específicas, em alguns } \\
\text { campi }\end{array}$ \\
\hline Baixo desempenho escolar & $\begin{array}{c}\text { Desmotivação ocasionada pelas sucessivas } \\
\text { repetências }\end{array}$ \\
\hline Problemas na família & $\begin{array}{l}\text { Demonstração de despreparo para o atendimento } \\
\text { com o público interno e externo }\end{array}$ \\
\hline Problemas de saúde & Cansaço físico e mental \\
\hline Outros & Falta de espaço de convivência para os estudantes \\
\hline
\end{tabular}

Fonte: Elaborado pelos autores (2020). 
Encontramos nos escritos de Arroyo (1991) e de Freire (1996) uma forte denúncia da desigualdade social perversa na luta constante de classes pelos direitos da emancipação política e social. A evasão educacional reside na falta de oportunidades para estudantes com e sem deficiências, que ocupam o mesmo ponto de intersecção. São os filhos e as filhas de famílias que não tiveram acesso ao desenvolvimento pessoal e profissional.

Portanto, nessa sociedade, o lugar da escola e da educação passa a ser o da negação do saber, que submete o operariado ao máximo de exploração e de embrutecimento, pois ao Estado excludente interessam súditos ignorantes e submissos (ARROYO, 1991). Nosso modelo educacional é a reprodução das relações de poder, com sua "grade" curricular e suas estruturas com raízes no capital; aprisiona e seleciona grupos que se destinam à sustentação da pirâmide excludente social, naturalizando o fracasso escolar, negando o direito à utopia, aos sonhos e às transformações.

Para Dore e Lüscher (2011), a complexidade do processo de evasão demanda soluções também complexas, de difícil execução e que envolvem a participação de diversos agentes sociais. Para tal enfrentamento, é necessário o fortalecimento das instituições públicas, como espaço de diálogo e de acolhimento, pela defesa da educação pública, gratuita, de qualidade e, acima de tudo, inclusiva. As práticas inclusivas devem ocupar espaços no fazer pedagógico, como é retratado por Fortes e Martins (2017, p.21), "a instituição de ensino precisa ser concebida como um ambiente educativo, onde trabalho e formação continuada dos profissionais de ensino não sejam atividades distintas, mas se constituindo num grande desafio".

As Políticas Públicas e Inclusivas para a Educação, em especial para a Educação Profissional, representam um avanço e uma conquista imensurável. Constatou-se o crescimento das matrículas dos estudantes com deficiência e a intensificação da luta pela permanência e pelo êxito desse público. Através do Acordão n 506/2013, ocorreu a elaboração dos Planos Estratégicos de Permanência e Êxito.

Com base nas informações contidas nos planos analisados, pudemos observar a diversidade de fatores que impulsionaram o fenômeno da evasão e a complexidade que envolve essa problemática educacional. Importante ressaltar que buscamos analisar alguns destes fatores, que também podem atingir, de maneira direta ou indireta, os 


\section{REVISTA}

Revista do Programa de Pós-Graduação em Educação da Unochapecó

ISSN 1984-1566 (on-line) ISSN 1415-8175 (impressa)

estudantes com deficiência durante sua caminhada pelo Ensino Médio Integrado. Os fatores apontados nos Planos apresentam similaridade, o que demonstra um problema presente em âmbito nacional, portanto, além de estratégias locais, é necessário pensar em estratégias que incluam toda a Rede Federal.

Ademais, sinalizamos um olhar para a Política de Assistência Estudantil, através do Decreto $n^{\circ}$ 7.234/2010 (BRASIL, 2010), que contempla muitos estudantes e favorece diretamente a permanência destes na instituição, porém tem apresentado uma drástica redução de recursos ao longo dos últimos anos. É notório o óbice institucional em cumprir a legislação referente aos direitos dos estudantes com necessidades educacionais específicas, bem como estudantes público-alvo da educação especial.

Destacamos, também, o Decreto $n^{\circ} 7.611 / 2011$ (BRASIL, 2011), que trata do Atendimento Educacional Especializado ( $A E E)$, tão necessário ao acolhimento e ao desenvolvimento dos estudantes. No entanto, ainda encontra barreiras para sua implementação nos IFs. Segundo o Decreto n6.253/2007 (BRASIL, 2007), que dispõe sobre o Fundo de Manutenção e Desenvolvimento da Educação Básica e de Valorização dos Profissionais da Educação - FUNDEB, o estudante público-alvo da educação especial pode apresentar dupla matrícula, implicando assim o cômputo tanto na educação regular da rede pública, quanto no Atendimento Educacional Especializado. Todavia, isto não ocorre nos Institutos Federais, o que pode comprometer o financiamento de mais recursos para a garantia da permanência dos estudantes com deficiência na Educação Profissional.

A implantação do NAPNE se confirma como um grande investimento nos IFs e possibilita significativa contribuição para a permanência dos estudantes com deficiência, haja vista que, nos regulamentos analisados, encontramos a "cultura da educação para convivência" e a corresponsabilidade na construção da ação educativa de inclusão. Por tudo isso, pontua Mantoan (2003, p. 34) "a inclusão é produto de uma educação plural, democrática e transgressora."

Além disso, as unidades tentam, mesmo com cortes e com bloqueios de recursos, cumprir a legislação, sem desprezar as especificidades dos IFs, no que tange à formação profissional do estudante e o drama das dificuldades na contratação de profissionais para garantia de um Atendimento Educacional Especializado e a consolidação da Educação Profissional Tecnológica Inclusiva. 


\section{CONSIDERAÇÕES FINAIS}

O presente estudo foi feito por meio de revisão bibliográfica documental pautada na literatura específica, analisando os caminhos da educação inclusiva e os fatores de evasão e de permanência durante a travessia no EMI da Rede Federal de Educação Profissional e Tecnológica.

Neste sentido, diante da escassez e da dificuldade de dados mais específicos para o público do referido estudo, os resultados revelam a complexidade da temática evasão e a corresponsabilidade institucional dos agentes educativos (docentes, família, equipe multiprofissional, gestão escolar, setor de assistência estudantil, setor pedagógico, representantes estudantis e demais setores acadêmicos). A construção e a execução dos planos de permanência e de êxito não podem ser alijadas das vozes estudantis.

Sinalizamos a importância da infraestrutura dos Institutos Federais (IFs) em relação às demais escolas brasileiras, por possuírem uma política de assistência estudantil, servidores com titulação em níveis de mestrado e de doutorado, arquitetura planejada que inclui laboratórios das variadas áreas do conhecimento, bibliotecas, salas climatizadas, banheiros e auditórios com acessibilidade, além de contar com a institucionalização do Núcleo de Apoio às Pessoas com Necessidades Específicas (NAPNE). Isto corrobora consideravelmente para a permanência dos estudantes. Porém, a falta da oferta do Atendimento Educacional Especializado (AEE) e a falta de formação continuada voltada para a educação especial e inclusiva, que envolva docentes e técnicos administrativos, são alguns desafios dos IFs, de forma a refletir diretamente na evasão dos estudantes com necessidades específicas. Constatamos a necessidade de mais estudos e de recursos no campo da Educação Profissional Tecnológica Inclusiva.

Ademais, vale ressaltar que desde 2014 vem ocorrendo consistente redução do volume de investimentos nos IFs, sendo intensificada no ano de 2019. Esta falta de investimento configura um retrocesso e um prejuízo educacional para toda a sociedade, tendo em vista que existem centenas de unidades que ainda demandam investimentos infraestruturais para sua consolidação. Além disso, a redução dos investimentos também atinge consideravelmente a Política de Assistência Estudantil, o que pode caracterizar em 
Revista do Programa de Pós-Graduação em Educação da Unochapecó

ISSN 1984-1566 (on-line) ISSN 1415-8175 (impressa)

mais um fator de evasão, pois os dados do Relatório Anual de Análise dos Indicadores de Gestão das Instituições Federais de Educação Profissional, Científica e Tecnológica, elaborado pelo Tribunal de Contas da União (2019), comprovam que 57,79\% dos estudantes da Rede Federal apresentam situação de vulnerabilidade econômica.

Importante registrar que, apesar das dificuldades e das fragilidades, os IFs vêm desempenhando sua função social ao longo dos seus dez anos de existência, contribuindo para a formação da classe trabalhadora do país. Como destaca Pacheco (2010, p.02), “derrubar as barreiras entre ensino técnico e o científico, articulando trabalho, ciência e cultura na perspectiva da emancipação humana, é um dos objetivos basilares dos Institutos".

Nesse contexto, torna-se imprescindível o fortalecimento da Educação Profissional Tecnológica Inclusiva através de mais investigações científicas e de estudos com olhar para o fosso educacional chamado evasão, e que apontem práticas exitosas, caminhos e estratégias de combate a tal fenômeno. Arroyo (1992, p. 49) nos lembra que "seria necessário pesquisar com maior atenção os componentes de nossa cultura escolar, especialmente aqueles que mais condicionam o fracasso-sucesso dos setores populares". É necessário e urgente repensar o nosso modelo educacional vigente, o Ensino Médio Integrado, a interdisciplinaridade e o lugar da inclusão. É preciso "tecer a rede" e, para isso, precisamos de um longo debate, pesquisas e investimentos.

Dessa forma, o estudo corrobora com o processo de educação inclusiva como um direito, mediante a valorização da diversidade e o registro dos saberes construídos na cultura da educação para convivência. Conclui-se que são relevantes ações que provoquem o acolhimento e a permanência dos estudantes em atividades de ensino, pesquisa e extensão, bem como possibilitem a corresponsabilidade na garantia de uma educação inclusiva.

\section{REFERÊNCIAS}

ARROYO, Miguel González. Revendo os vínculos entre trabalho e educação: elementos materiais da formação humana. In: SILVA, Tomaz Tadeu da. (Org.). Trabalho, educação e prática social: por uma teoria da formação humana. Porto Alegre: Artes Médicas, 1991. 


\section{REVISTA}

Revista do Programa de Pós-Graduação em Educação da Unochapecó

ISSN 1984-1566 (on-line) ISSN 1415-8175 (impressa)

ARROYO, Miguel Gonzalez. Fracasso-sucesso: o peso da cultura escolar e do ordenamento da educação básica. In: ABRAMOWICZ, A.; MOLL, J. (Orgs.) Para além do fracasso escolar. Campinas, SP: Papirus, 1992.

BRASIL. Constituição da República Federativa do Brasil. Brasília, DF: Senado: Centro Gráfico, 1988. Disponível em:

http://www.planalto.gov.br/ccivil_03/constituicao/constituicao.htm. Acesso em: 20 fev. 2020.

BRASIL. Lei n 9.394, de 20 de dezembro de 1996. Estabelece as diretrizes e bases da educação nacional. Brasília: Presidência da República. Disponível em: www.planalto.gov.br/ccivil_03/leis/l9394.htm. Acesso em: 20 fev. 2020.

BRASIL. Decreto n 6.253, de 13 de novembro de 2007. Dispõe sobre o Fundo de Manutenção e Desenvolvimento da Educação Básica e de Valorização dos Profissionais da Educação - FUNDEB, regulamenta a Lei no 11.494, de 20 de junho de 2007, e dá outras providências. Brasília: Presidência da República. Disponível em: http://www.planalto.gov.br/ccivil_03/_Ato2007-2010/2007/Decreto/D6253.htm. Acesso em: 11 maio 2020.

BRASIL. Lei no 11.892/2008, de 29 de dezembro de 2008. Institui a Rede Federal de Educação Profissional, Científica e Tecnológica, cria os Institutos Federais de Educação, Ciência e Tecnologia, e dá outras providências. Brasília: Presidência da República. Disponível em: http://www.planalto.gov.br/ccivil_03/_at02007-2010/2008/lei//11892.htm. Acesso em: 11 maio 2020.

BRASIL. Decreto $\mathbf{n}^{\circ} \mathbf{7 . 2 3 4}$, de 19 de julho de 2010. Dispõe sobre o Programa Nacional de Assistência Estudantil - PNAES. Brasília: Presidência da República. Disponível em: http://www.planalto.gov.br/ccivil_03/_ato2007-2010/2010/decreto/d7234.htm. Acesso em: 20 abr. 2020.

BRASIL. Decreto $\mathbf{n}^{0} \mathbf{7 . 6 1 1}$, de 17 de novembro de 2011. Dispõe sobre a educação especial, o atendimento educacional especializado e dá outras providências. Brasília: Presidência da República. Disponível em: http://www.planalto.gov.br/ccivil_03/_ato20112014/2011/decreto/d7611.htm. Acesso em: 24 abr. 2020.

BRASIL. Acordão nº 506 de 13 de março de 2013. TCU. Disponível em: http://www.ifto.edu.br/portal/docs/dae/permanencia/acordao-506-2013.pdf. Acesso em: 05 maio 2020.

BRASIL. Lei n 13.146, de 06 de julho de 2015. Institui a Lei Brasileira de Inclusão da Pessoa com Deficiência (Estatuto da Pessoa com Deficiência). Brasília: Presidência da República. Disponível em: http://www.planalto.gov.br/ccivil_03/_ato2015-2018/2015/lei/l13146.htm Acesso em: 23 fev. 2020. 
Revista do Programa de Pós-Graduação em Educação da Unochapecó

ISSN 1984-1566 (on-line) ISSN 1415-8175 (impressa)

BRASIL. Relatório Anual de Análise de Indicadores de Gestão das Instituições Federais de Educação Profissional Científica e Tecnológica. 2019. Disponível em:

http://portal.mec.gov.br/docman/julho-2019-pdf/117321-caderno-de-indicadores-2019tcu/file. Acesso em: 21 abr. 2020.

FACHIN, Odilia. Fundamentos de Metodologia. 4 ed. São Paulo: Saraiva, 2006.

FORTES, Vanessa Gosso Gadelha de Freitas; MARTINS, Lúcia de Araújo Ramos. Formação Continuada de Professores do Ensino Médio Integrado do IFRN na Perspectiva da Inclusão de Alunos com Deficiência Visual. Olhares: Revista Do Departamento De Educação Da Unifesp, v.5, n.2, p.31-53, 2017.Disponível em:

https://periodicos.unifesp.br/index.php/olhares/article/view/749/262. Acesso em: 27 maio 2020.

FREIRE, Paulo. Pedagogia da Autonomia: saberes necessários à prática educativa. São Paulo: Paz e Terra, 1996.

INEP. Censo da Educação Básica 2019: notas estatísticas. 2019.Disponível em: http://portal.inep.gov.br/informacao-da publicacao/-

lasset_publisher/6JYIsGMAMkW1/document/id/6798882. Acesso em: 26 abr. 2020.

INSTITUTO FEDERAL DE EDUCAÇÃO, CIÊNCIA E TECNOLOGIA DO CEARÁ. Plano Estratégico para Permanência e Êxito dos Estudantes do IFCE 2017-2024. Fortaleza: PróReitoria de Ensino do IFCE, 2017.

INSTITUTO FEDERAL DE EDUCAÇÃO, CIÊNCIA E TECNOLOGIA DO PARÁ. Plano Estratégico de permanência e de êxito dos Estudantes do IFPA. 2020. Disponível em: https://slideplayer.com.br/slide/16315173/. Acesso em: 03 maio 2020.

INSTITUTO FEDERAL DE EDUCAÇÃO, CIÊNCIA E TECNOLOGIA DO RIO GRANDE DO SUL. Regulamento dos Núcleos de Atendimento às Pessoas com Necessidades Específicas. 2014. Disponível em: https://ifrs.edu.br/wp-content/uploads/2017/09/Resolucao-20-14.pdf. Acesso em: 10 abr. 2020.

INSTITUTO FEDERAL DE EDUCAÇÃO, CIÊNCIA E TECNOLOGIA DE RONDÔNIA. Regulamento dos Núcleos de Atendimento às Pessoas com Necessidades Específicas. 2016. Disponível em: https://portal.ifro.edu.br/component/phocadownload/file/251regulamento-napne-2016?tmpl=component. Acesso em: 10 abr. 2020.

DORE, Rosemary; LÜSCHER, Ana Zuleima. Permanência e evasão na educação técnica de nível médio em Minas Gerais. Cadernos de pesquisa, v. 41, n. 144, p. 770-789, 2011.

Disponível em: http://www.scielo.br/pdf/cp/v41n144/v41n144a07.pdf. Acesso em: 24 abr. 2020.

GALASSO, Bruno José Betti et al. Processo de Produção de Materiais Didáticos Bilíngues do Instituto Nacional de Educação de Surdos. Rev. bras. educ. espec., Bauru, v. 24, n. 1, p. 
Revista do Programa de Pós-Graduação em Educação da Unochapecó

ISSN 1984-1566 (on-line) ISSN 1415-8175 (impressa)

59-72, mar. 2018. Disponível em:

$<$ http://www.scielo.br/scielo.php?script=sci_arttext\&pid=S1413-

65382018000100059\&lng=en\&nrm=iso >. Acesso em: 12 abr. 2021.

MACHADO, Erica Esch; TEIXEIRA, Dirceu Esdras; GALASSO, Bruno José Betti. Concepção do Primeiro Curso Online de Pedagogia em uma Perspectiva Bilíngue Libras-Português.

Rev. bras. educ. espec., Marília, v. 23, n. 1, p. 21-36, mar. 2017. Disponível em:

$<$ http://www.scielo.br/scielo.php?script=sci_arttext\&pid=S1413

65382017000100021\&lng=en\&nrm=iso >. Acesso em: 12 abr. 2021.

MANTOAN, Maria Teresa Eglér. Inclusão escolar: O que é? Por que? Como fazer? São Paulo: Moderna, 2003.

MINAYO, Maria Cecília de Souza (org.). Pesquisa social: teoria, método e criatividade. 26 ed. Petrópolis, RJ: Vozes, 2007.

PACHECO, Eliezer. Os Institutos Federais: uma revolução na educação profissional e tecnológica. 2010. Disponível em: http://memoria.ifrn.edu.br/handle/1044/1013. Acesso em: 23 abr. 2020.

ROCHA, Aline dos Santos. Adaptação do Edifício do Antigo Colégio Marista à Sede da

Reitoria do IFBA. 2013.143 f. Dissertação (Mestrado Profissional em Conservação e Restauração de Monumentos e Núcleos Históricos) - Faculdade de Arquitetura, Universidade Federal da Bahia, Salvador, 2013.

SILVA, A.R.X.; CARVALHO, M. C. A.; GONÇALVES, R. M. Mapeamento e análise das produções científicas que versam sobre as políticas de assistência estudantil no contexto do programa nacional de assistência estudantil. Revista Pedagógica, v. 23, p. 1-30, 2021. DOI http://dx.doi.org/10.22196/rp.v23i0.5529

Recebido em: 10-02-2021

Aprovado em: 16-04-2021

Publicado em: 03-05-2021 